\title{
Secretion Effect of Estrogen of Different Growth Stages of Silkworm (Bombyx mori L.)
}

\author{
Kang-Sun Ryu ${ }^{1, *}$, Heui-Sam Lee ${ }^{1}$, Kee-Young Kim ${ }^{1}$, Mi-Ja Kim ${ }^{1}$, Hong-Guen Oh$^{2}$, and Pil-Don Kang ${ }^{1}$ \\ ${ }^{I}$ Department of Agricultural Biology, National Academy of Agricultural Science, RDA, Suwon 441-853, Korea \\ ${ }^{2}$ Huvet. co. Ltd, Iksan. Korea
}

(Received 25 January 2011; Accepted 08 March 2011)

The average life expectancy has continuously increased with the development of medical industry. As women get older, they experience the deficit of estrogen caused by decreased function of ovarian. Specifically, they suffer from temporary fever because of unstable vasomotion and, in the long term experience, degeneration of urogenital organs, tooth loss, arteriosclerosis, demantia, snores and so on. Because of these symptoms the estrogen medical supply is getting required. Along with this, many studies have conducted to find out substitutional medicals without any side effects. This research was carried out to find out such substitutable materials. For the purpose of study, we examined the change of estrogen using the rats fed with the pupa powder immediately before the eclosion, eclosed adult, the pupa extract immediately before the eclosion, and the silkworm powder prepared at $3^{\text {rd }}$ day of $5^{\text {th }}$ instar. The result showed no significant chance in weight, feeding and water intake quantity among variables. However, the estrogen hormone secretion effects was very high at $73 \mathrm{pg} / \mathrm{ml}$ in the rats fed with the freeze-dried powder of the Yeonnokjam male pupa prepared immediately before the eclosion, compared with the control at $59 \mathrm{pg} / \mathrm{ml}$. The next was Yangwonjam male adult at $71 \mathrm{pg} / \mathrm{ml}$.

Key words: Silkworm, Silkworm pupae, Estrogen hormone

\footnotetext{
*To whom the correspondence addressed

Department of Agricultural Biology, National Academy of Agricultural Science, RDA, Suwon 441-853, Republic of Korea

Tel: +82-31-290-8518; Fax: +82-31-290-8516;

E-mail: ryuks@korea.kr
}

\section{Introduction}

The average life expectancy in South Korea has continuously increased with the development of medical industry. According to an educational program data for the American pharmacists, about $1 / 3$ of the American women spend their lives with a menopause condition. In the case of Korea, menopause begins little bit earlier, but it is assumed that Korean women will have similar pattern with American women because of increased life expectancy. The women in the menopause stage have stabilized lives and still maintain the energy to enjoy their lives. Unfortunately, the unpleasant experience of the critical age condition that $80 \%$ of women experience deteriorates the quality of their lives and confidence (Oldenhave et al., 1993). As women get older, they experience the deficit of estrogen caused by decreased function of ovarian. Specifically, they suffer from temporary fever because of unstable vasomotion and in the long term experience degeneration of urogenital organs, tooth loss, arteriosclerosis, dementia, snores, and so on.

These symptoms caused by deficit of estrogen are called Pre- AND Post- menopausal syndrome and PMS (Clarke et al., 1992; Cumming et al., 1990). Conjugated equine estrogen, CEE, or chemosynthesis medical supply has been used recently to reduce or cure these symptoms. Especially, CEE, which has been used the most frequently, has improved the symptoms caused by temporary fever (hot flush) or degeneration of urogenital organs like dyspareunia (Pornel et al., 1996) (Wren et al., 1996). Also, it improves the function of liver; therefore, it increases HDL cholesterol and decreases total and LDL cholesterol (Adami et al., 1993; Meschia et al., 1998). That is, if estrogen is injected to the women in the menopause stage, it can reduces the illness due to the unstable vasomotion and degeneration of urogenital organs and prevent from osteoporosis and the symptoms related to cardiovascular 
activity (Maddox et al., 1998). However, according to research by Women's Health Initiative, which had been conducted for five years with 16,000 people, the animal origin estrogen medical supply lowered colon cancer by $37 \%$ and fracture by $2 \%$, but it increased breast cancer by $26 \%$, heart deasease by $29 \%$, a fit by $41 \%$ and blood clotting two times higher (Writing, 2002). Because of these fatal side effects, recently FDA suggests to forbid its long term prescription.

In Korea, several Chinese medications have traditionally been utilized for the treatment of erection dysfunction, but their effect has never been scientifically proved until recently. It has been reported that the alcohol extract of male pupae showed that the testosterone levels in serum increased by $19 \%$, that of testicle increased by $200 \%$, and athletic endurance of the rats by $6 \%$, suggesting positive tonic effect of the pupae prepared at the stage of 14 days after metamorphosis (Ryu et al., 2002).

In this study, we fed SD rats the silkworm larvae powder prepared at the $3^{\text {rd }}$ day of $5^{\text {th }}$ instar, the silkworm powder of spinning start, the pupae powder immediately before the eclosion, the powder prepared from eclosed adult to test the estrogen secretion efficacy on the rats. These were prepared from both sexes and several varieties.

\section{Materials and Methods}

Preparation of silkworm according to the growth stage The silkworms used for the experiment were Yangwonjam and Yeonnokjam that are successively preserved as the silkworm leading variety in Korea. Yangwonjam is sex-limited silkworm bred with larval marker. This variety shows body marker on the back of only female larvae and the marker are obvious enough for the non-specialists to separate sex casually. Yeonnokjam is green color specific variety. These silkworms were reared in spring season at 2010 in National Academy Agricultural Science. The 3rd day of 5th instar larvae and spinning start larvae were quickly frozen with the liquid nitrogen, and the pupae immediately before the eclosion and eclosed adult were frozen in deep freezer. These samples were subjected to fine powder with grinder mixer machine

\footnotetext{
Animals

Six-week-old male mice of SD-strain were purchased from SAMTAKO Bio Korea and were grown. Each five rats were reared in a cage and maintained at $22^{\circ} \mathrm{C}$ and $50 \%$ of room temperature and humidity, respectively (12 hrs of light and dark cycle) with free access to rodent diet (SAMTAKO Bio Korea) and sterilized water.
}

Table 1. The diet of various sample additives

\begin{tabular}{ccc}
\hline Treatment & Rats & Diet \\
\hline Control(Con) & 5 & Normal diet \\
\hline $\begin{array}{c}5 \text { instar } 3^{\text {rd }} \text { days male larvae of } \\
\text { Yangwonjam (L53M) }\end{array}$ & 5 & Mixed 0.7\% \\
\hline $\begin{array}{c}5 \text { instar } 3^{\text {rd }} \text { days female larvae of } \\
\text { Yangwonjam (L53F) }\end{array}$ & 5 & Mixed 0.7\% \\
\hline $\begin{array}{c}\text { male pupae before the eclosion of } \\
\text { Yangwonjam (P14YWM) }\end{array}$ & 5 & Mixed 0.7\% \\
\hline $\begin{array}{c}\text { female pupae before the eclosion of } \\
\text { Yangwonjam (P14YWF) }\end{array}$ & 5 & Mixed 0.7\% \\
\hline $\begin{array}{c}\text { male adult of Yangwonjam (AYWM) } \\
\text { female adult of Yangwonjam (AYWF) }\end{array}$ & 5 & Mixed 0.7\% \\
\hline $\begin{array}{c}\text { male pupae before the eclosion of } \\
\text { Yeonnokjam (P14YRM) }\end{array}$ & 5 & Mixed 0.7\% $0.7 \%$ \\
\hline $\begin{array}{c}\text { female pupae before the eclosion of } \\
\text { Yeonnokjam (P14YRF) }\end{array}$ & 5 & Mixed 0.7\% \\
\hline Total 9 groups & 45 animals \\
\hline
\end{tabular}

When rats were grown to weight of $210 \sim 240 \mathrm{~g}$, they were divided into siz groups ( $\mathrm{n}=5$ per group) and fed the diets supplemented with various additives for 4 weeks as shown in Table 1. The blood serum was taken after fasting for $16 \mathrm{hrs}$ before the end of experiment.

\section{Quantification of estrogen}

The rats were fasted for 16 hours before autopsy. The blood serum was taken at abdominal vein after incised the abdomen with ether treatment. This serum was separated by centrifuge at $2500 \mathrm{rpm}, 15 \mathrm{~min}$. The level of testosterone was analyzed at UB Medical Institute.

\section{Results and Discussions}

\section{Change in body weight}

Our analysis focused on the comparison of change in body weights between the treated group and the control group. The result did not show much difference between the two groups regardless of time changes (Fig. 1). There was no apparent weight loss in the control group, indicating that the nutrition was not a relative matter.

\section{Change of feed intake}

The daily diet for the experiments was $200 \mathrm{~g}$ per cage. After $24 \mathrm{hrs}$ of food supply we subtracted the remainder from $200 \mathrm{~g}$ per cage. Then, we divided the amount by the number of animals in the cage to obtain the quantity of feed intake. This result shows no significant difference in feed intake between the groups (Fig. 2). 


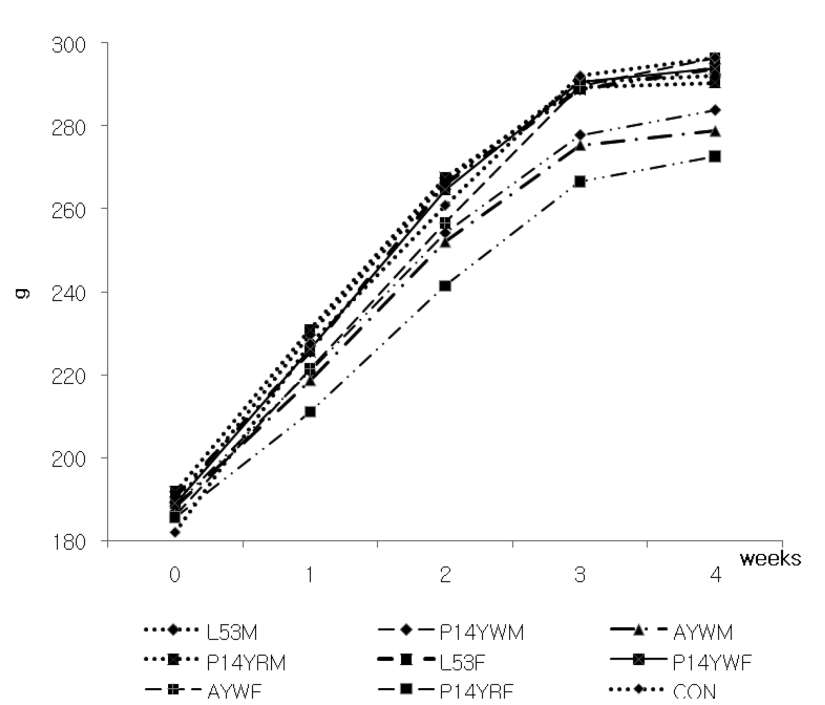

Fig. 1. Body weight changes in rats fed diets of the silkworm for 4 weeks.

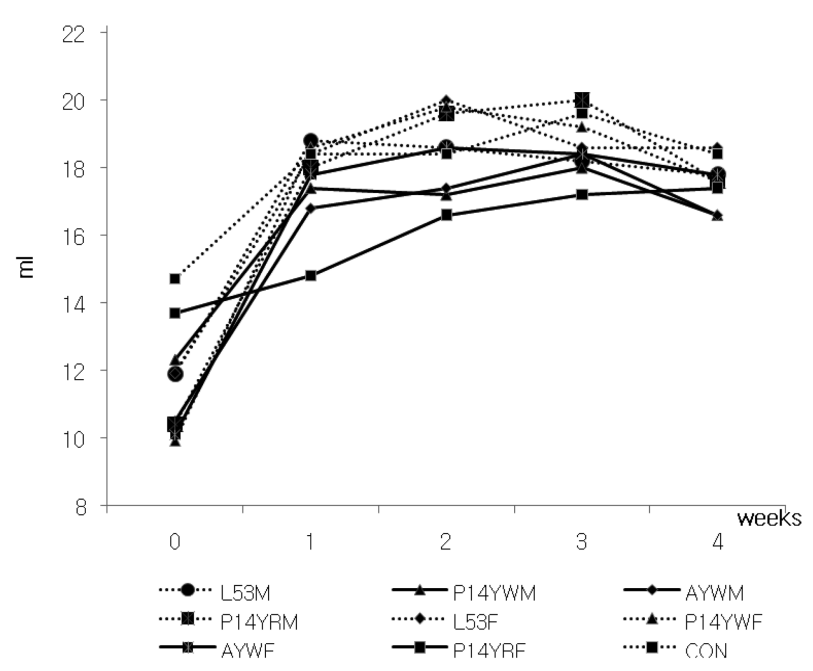

Fig. 2. Change in feed intake in rats fed diets of the silkworm for 4 weeks.

\section{Change of water intake}

We prepared $500 \mathrm{ml}$ water in the cage the day before quantification of water intake. The total quantity consumed was divided into rat number to obtain per-rat intake. Among the treatments, the rats treated with the pupae powder prepared immediately before the eclosion consumed much larger amount of water, but was not statistically significant (Fig. 3).

\section{Serum estrogen level}

We compared the estrogen secretion effect of the lyophilized powders from silkworm larvae of male and female, pupae and unmated moths. As explained above,

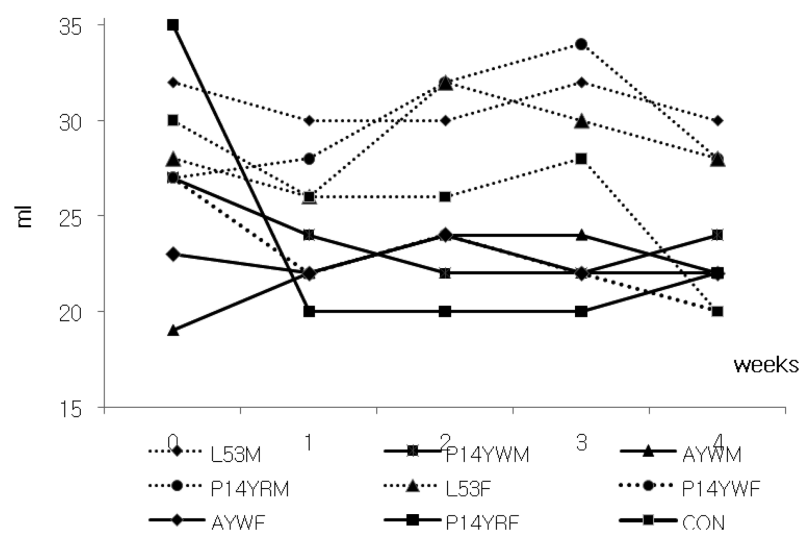

Fig. 3. Change in water intake in rats fed diets of the silkworm for 4 weeks.

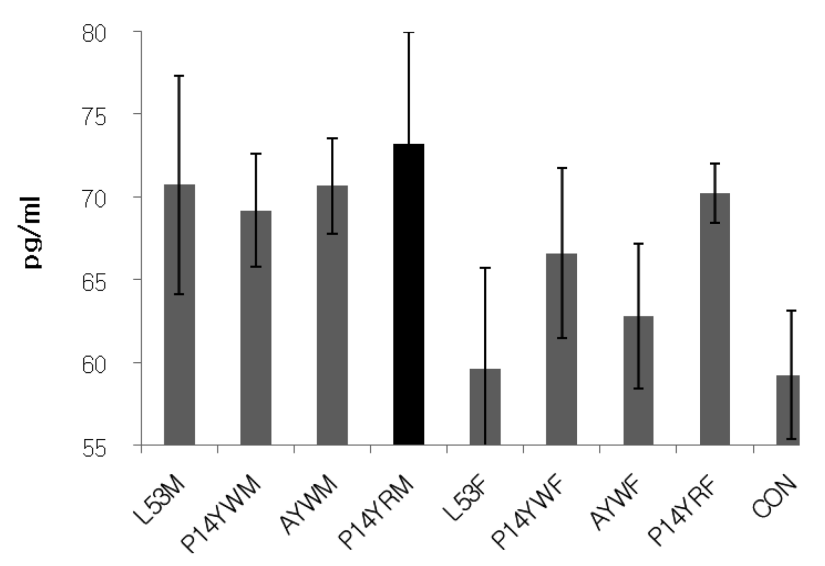

Fig. 4. Serum estrogen level of rats treated with sample diets for 4 weeks.

we used pupae sample from pupae immediately before the eclosion. Thus, the pupae utilized in this study in fact are internally moths, with the appearance of pupae. In the rats fed $0.7 \%$ with sample powder. Among these samples, the powder of Yeonrokjam pupae immediately before the eclosion (P14YRM) showed lager increase with $73 \mathrm{pg} / \mathrm{ml}$ than the control group with $59 \mathrm{pg} / \mathrm{ml}$, which fed the normal diet without silkworm powder (Fig. 4). The next is the male adult of Yangwonjam (AYWM) and 5 instar $3^{\text {rd }}$ day male larvae of Yangwonjam (L53M). These three samples were shown significantly different about $5 \%$ levels. As this result, the freeze drying pupa powder was confirmed to promote the secretion of the estrogen hormone. And this result is very similar with effect of testosterone secretary by male pupae (Ryu et al., 2002). The estrogens and juvenile hormone has similar mechanisms of action (Biggers et. al., 2004). In the present study, we found that larvae and pupae of silkworm are related with secretion of the estrogen and testosterone. 


\section{References}

Adami S, Rossini M. Zzmberian N, Bertoldo F, Dorizzi R, Lo Cascio V (1993) Long-term effects of transdermal and oral estrogens on serum lipids and lipoproteins in postmenopausal women. Maaturitas 17, 191-196.

Biggers WJ, Laufer H (2004) Identification of juvenile hormone-active alkylphenols in the Lobster Homarus americanus and in marine sediments. Biol.Bull 206, 13-24.

Clarke AP, Shuttinga JA (1992) Targeted estrogen/progestron replacement therapy for osteoporosis: calculation of health care cost savings. Osteoporosis Int. 2, 195-200.

Cummings SR, Rubin SM, Black D (1990) The future of hip fractures in the United States: numbers, costs and potential effects of postmenopausal esterogen. Clin Orthop. 252, 163166.

Maddox RW, Carson DS, Barnes CI (1998) Estrogens and postmenopausal women. U S Pharmacist 23, 141-150.

Mashchak CA, Lobo R A, Dozono-Takano R, Eggena P, Nakamura RM, Brenner PF, Mishell Jr DR (1982) Comparison of phamacodynamic properties of various estrogen formulations. An. J. Obstet. Gynecol. 144, 511-518.

Meschia M, Bruschi F, Soma M, Amicarelli F, Paoletti R, Crosignani P (1998) Effect of oral and transdermal hormone replacement therapy on lipoprotein(A) and lipids; a randomized controlled trial. Menopause. 5, 157-162.

Oldenhave AL, Jaszmann J, Haspels AA, Everaerd WT (1993) Impact of climactric on well being. A survey based on 5213 women 39 to 60 years old, Am.J.Obstet Gynecol. 168, 772780.

Pornel B (1996) Efficacy and safety of Menorest in two positive-controlled studies, Eur. J. Obstet Gynecol. Reprod. Biol. 64(suppl 1), s35-s37.

Ryu KS, Ahn MY, Lee HS, Kim IK, Kim JW,. Kim SH, Choi JH (2002) The tonic effect of the extract from male silkworm(Bombyx mori L.) pupae on rats. Int.J.Indust. Entomol. 5(1), 123-126.

U.S. Pharmacist Continuing Education (2001) The new science of estrogen recepttors. ACPE Program No. 430-00099-004-H01, US Pharmacist.

Wren B (1996) Menorest: a clinical overview. Int. J. Gynaecol. Obstet, 52(suppl 1) s27-s29.

Writing group for the women's health initiative investigators (2002) Risks and benefits of estrogen plus progestin in healthy postmenopausal women: principal results from the women's Health initiatives radomized controlled trial. JAMA 288, 321-323. 